\title{
Common Strawberry Diseases in Florida
}

\section{Fungal}

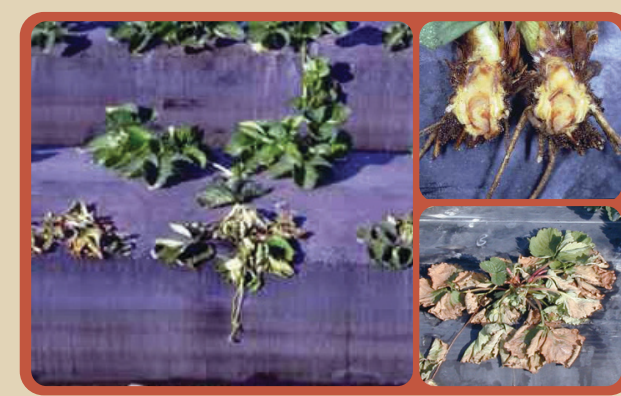

Phytophthora crown rot

(Phytophthora cactorum)

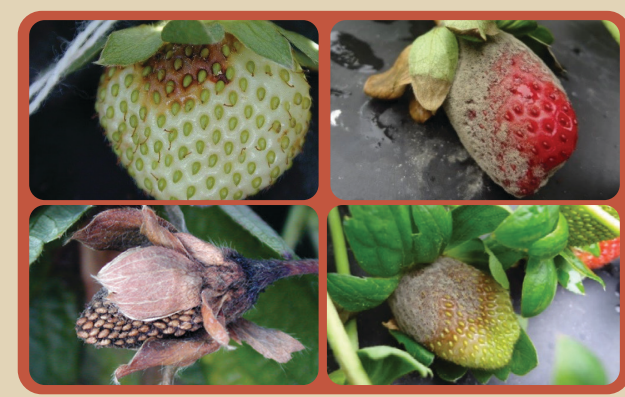

Botrytis fruit rot

(Botrytis cinerea)

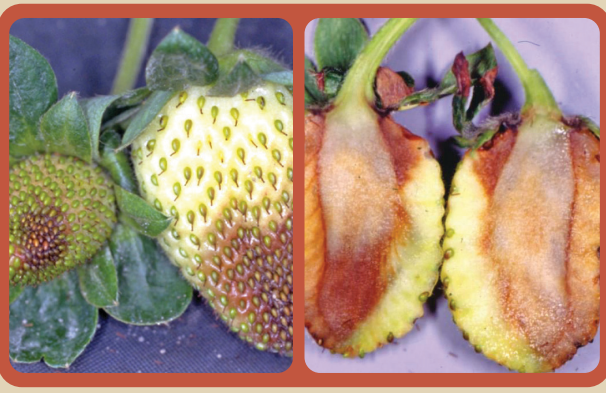

Leather rot

(Phytophthora cactorum P. nicotianae)

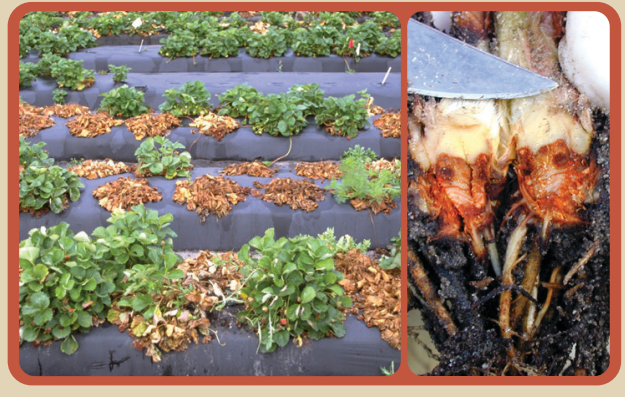

Colletotrichum crown rot

(Colletotrichum gloeosporioides)

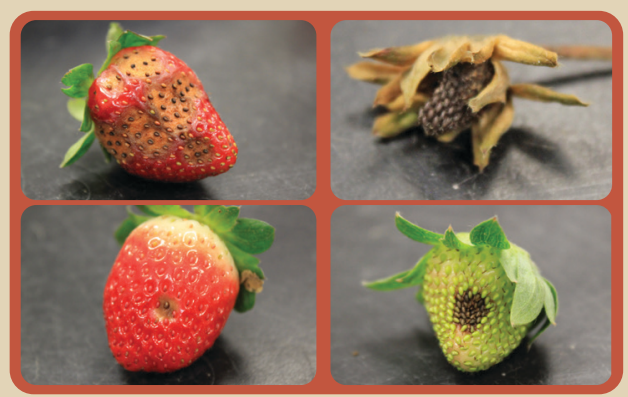

Anthracnose fruit rot (Colletotrichum acutatum)

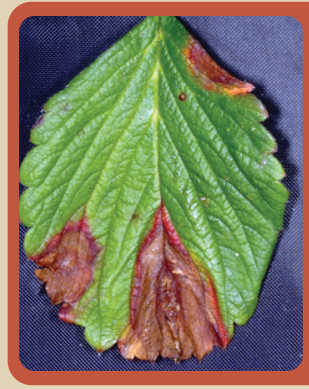

Phomopsis leaf blight and soft rot (Phomopsis obscurans)

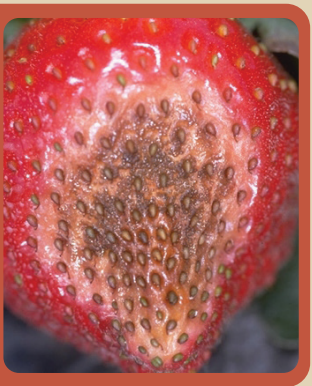

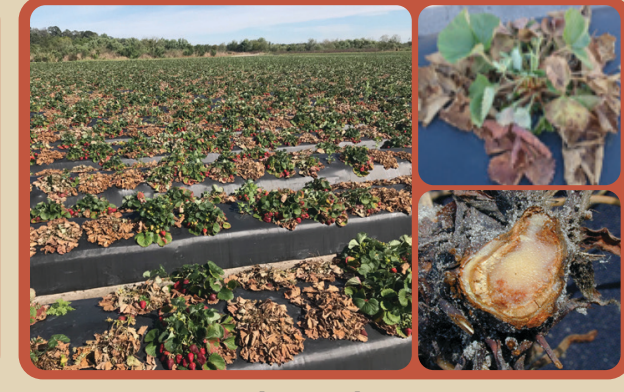

Charcoal rot

(Macrophomina phaseolina)

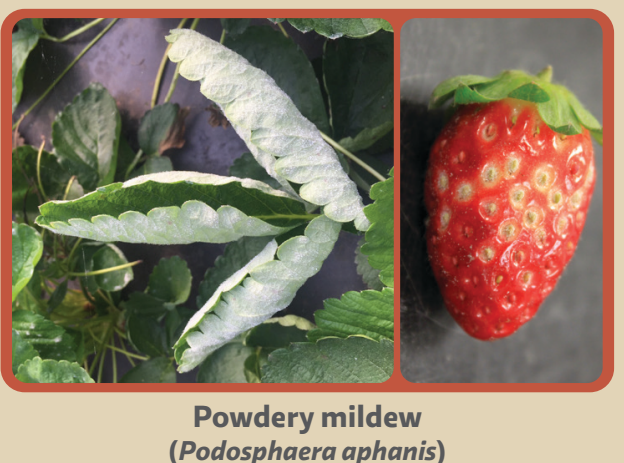

(Podosphaera aphanis)

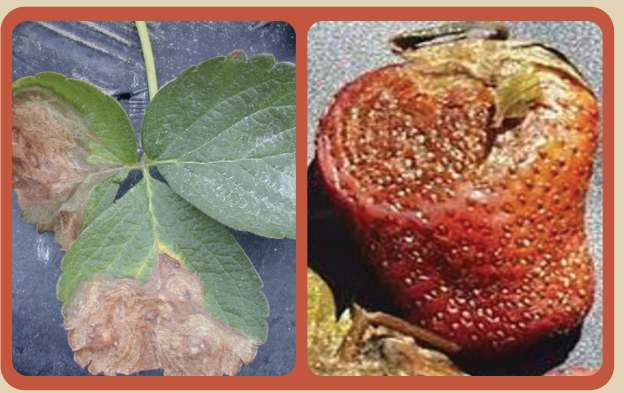

Stem-end rot and leaf blotch (Gnomonia comari)

\section{Bacterial}

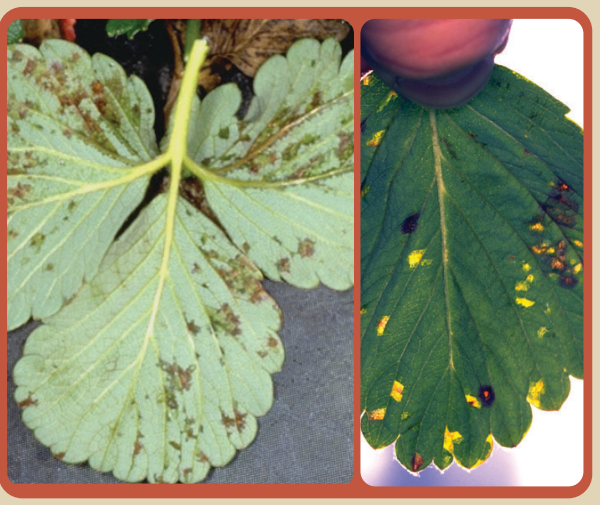

Angular leaf spot

(Xanthomonas fragariae)

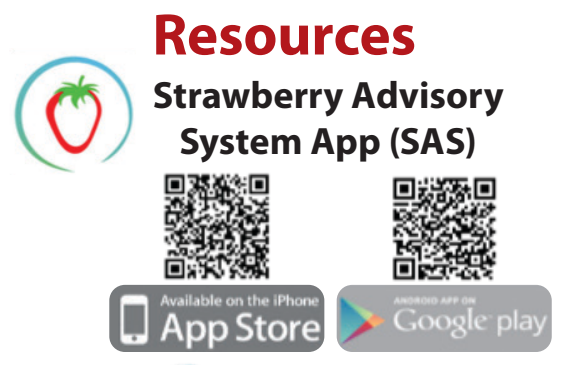

(4) AgroClimate

\section{f@UFSTRAWBERRY}

\section{For more information} NATALIA PERES

Professor

UF/IFAS Plant Pathology Department nperes@ufl.edu

CLYDE FRAISSE

Professor

UF/IFAS Agricultural \& Biological Engineering cfraisse@ufl.edu 
Conventional Fungicides

(listed by FRAC group)
FRAC

Group $^{1}$

Topsin (thiophanate-methyl)

Rovral (iprodione)

Orbit (propiconazole)

Mettle (tetraconazole)

Rally (myclobutanil)

Procure (triflumizole)

Ridomil (mefenoxam)

Fontelis (penthiopyrad)

Kenja (isofetamid)

Scala (pyrimethanil)

Abound (azoxystrobin)

Cabrio (pyraclostrobin)

Flint (trifloxystrobin)

Evito (fluoxastrobin)

Quintec (quinoxyfen)

Elevate (fenhexamid)

Aliette (fosetyl-Al)

phosphites (many brands)

Quilt Xcel (azoxystrobin + propiconazole)

Luna Tranquility (fluoypram + pyrimethanil)

Merivon (fluxapyroxad + pyraclostrobin)

Pristine (boscalid + pyraclostrobin)

Switch (cyprodinil + fludioxonil)

copper (many brands)

sulfur (many brands)

Thiram (thiram)

Captan (captan)

Captevate (captan + fenhexamid)

Actigard (acibenzolar-s-methyl)

Torino (cyflufenamid)

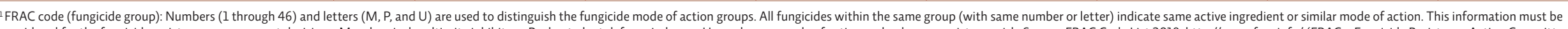

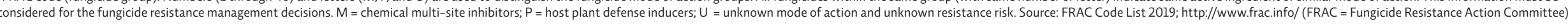

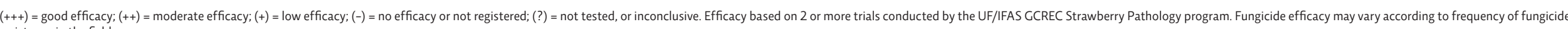
resistance in the field.

Common Diseases of Strawberries

\begin{tabular}{|c|c|c|c|c|c|c|}
\hline $\begin{array}{l}\text { Phytophthora } \\
\text { Crown Rot }\end{array}$ & $\begin{array}{l}\text { Colletotrichum } \\
\text { Crown Rot }\end{array}$ & Botrytis Fruit Rot & Anthracnose & Powdery Mildew & Leather Rot & Angular Leaf Spot \\
\hline- & ++ & - & - & - & - & - \\
\hline- & - & ++ & - & - & - & - \\
\hline- & $?$ & - & ++ & + & - & - \\
\hline- & $?$ & - & + & + & - & - \\
\hline- & - & - & - & + & - & - \\
\hline+++ & - & - & - & - & +++ & - \\
\hline- & - & ++ & - & ++ & - & - \\
\hline- & - & +++ & - & - & - & - \\
\hline- & - & + & - & - & - & - \\
\hline- & ++ & + & ++ & + & - & - \\
\hline- & - & - & - & +++ & - & - \\
\hline- & - & ++ & - & - & - & - \\
\hline+ & - & - & - & - & + & - \\
\hline++ & - & - & - & - & + & - \\
\hline- & ++ & - & ++ & ++ & - & - \\
\hline- & - & +++ & - & $?$ & - & - \\
\hline- & ++ & ++ & ++ & +++ & - & - \\
\hline- & ++ & + & ++ & ++ & - & - \\
\hline- & ++ & +++ & ++ & - & - & - \\
\hline- & - & - & - & +++ & - & - \\
\hline
\end{tabular}

Fungicide recommendations on this poster are provided for general information only. All fungicides must be applied in accordance with label directions. Not all fungicides or all formulations avaliable for strawberry are listed in the table. The use of trade names in this publication is solely for the purposs of provid 2 s.
abel.

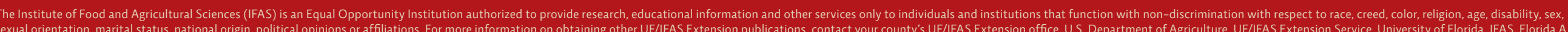
M University Cooperative Extension Program, and Boards of County Commissioners Cooperating. Nick T. Place, dean for UF/IFAS Extension. 